\title{
Exploring mechanisms of change in schema therapy for chronic depression
}

Citation for published version (APA):

Renner, F., DeRubeis, R. J., Arntz, A., Peeters, F., Lobbestael, J., \& Huibers, M. J. H. (2018). Exploring mechanisms of change in schema therapy for chronic depression. Journal of Behavior Therapy and Experimental Psychiatry, 58, 97-105. https://doi.org/10.1016/j.jbtep.2017.10.002

Document status and date:

Published: 01/03/2018

DOI:

10.1016/j.jbtep.2017.10.002

Document Version:

Publisher's PDF, also known as Version of record

Document license:

Taverne

Please check the document version of this publication:

- A submitted manuscript is the version of the article upon submission and before peer-review. There can be important differences between the submitted version and the official published version of record.

People interested in the research are advised to contact the author for the final version of the publication, or visit the DOI to the publisher's website.

- The final author version and the galley proof are versions of the publication after peer review.

- The final published version features the final layout of the paper including the volume, issue and page numbers.

Link to publication

\footnotetext{
General rights rights.

- You may freely distribute the URL identifying the publication in the public portal. please follow below link for the End User Agreement:

www.umlib.nl/taverne-license

Take down policy

If you believe that this document breaches copyright please contact us at:

repository@maastrichtuniversity.nl

providing details and we will investigate your claim.
}

Copyright and moral rights for the publications made accessible in the public portal are retained by the authors and/or other copyright owners and it is a condition of accessing publications that users recognise and abide by the legal requirements associated with these

- Users may download and print one copy of any publication from the public portal for the purpose of private study or research.

- You may not further distribute the material or use it for any profit-making activity or commercial gain

If the publication is distributed under the terms of Article $25 \mathrm{fa}$ of the Dutch Copyright Act, indicated by the "Taverne" license above, 


\title{
Exploring mechanisms of change in schema therapy for chronic depression
}

\author{
Fritz Renner ${ }^{\mathrm{a}, \mathrm{b}, *}$, Robert DeRubeis $^{\mathrm{c}}$, Arnoud Arntz $^{\mathrm{d}}$, Frenk Peeters ${ }^{\mathrm{e}, \mathrm{f}}$, Jill Lobbestael ${ }^{\mathrm{b}}$, \\ Marcus J.H. Huibers ${ }^{c, g}$ \\ a MRC Cognition and Brain Sciences Unit, Cambridge, United Kingdom \\ b Department of Clinical Psychological Science, Maastricht University, The Netherlands \\ c Department of Psychology, University of Pennsylvania, Philadelphia, PA, United States \\ d Department of Clinical Psychology, University of Amsterdam, The Netherlands \\ e Department of Psychiatry and Neuropsychology, University Hospital Maastricht, The Netherlands \\ f School for Mental Health and Neuroscience, Faculty of Health, Medicine and Life Sciences, Maastricht University, The Netherlands \\ ${ }^{g}$ Department of Clinical Psychology, VU University Amsterdam, The Netherlands
}

\section{A R T I C L E I N F O}

\section{Keywords:}

Mechanisms of change

Schema therapy

Chronic depression

Negative core-beliefs

Therapeutic alliance

\begin{abstract}
A B S T R A C T
Background and objectives: The underlying mechanisms of symptom change in schema therapy (ST) for chronic major depressive disorder (cMDD) have not been studied. The aim of this study was to explore the impact of two potentially important mechanisms of symptom change, maladaptive schemas (proxied by negative idiosyncratic core-beliefs) and the therapeutic alliance.

Methods: We drew data from a single-case series of ST for cMDD. Patients with cMDD $(\mathrm{N}=20)$ received on average 78 repeated weekly assessments over a course of up to 65 individual sessions of ST. Focusing on repeated assessments within-individuals, we used mixed regression to test whether change in core-beliefs and therapeutic alliance preceded, followed, or occurred concurrently with change in depressive symptoms.

Results: Changes in core-beliefs did not precede but were concurrently related to changes in symptoms. Repeated goal and task agreement ratings (specific aspects of alliance) of the same session, completed on separate days, were at least in part associated with concurrent changes in symptoms.

Limitations: By design this study had a small sample-size and no control group.

Conclusions: Contrary to what would be expected based on theory, our findings suggest that change in corebeliefs does not precede change in symptoms. Instead, change in these variables occurs concurrently. Moreover, alliance ratings seem to be at least in part colored by changes in current mood state.
\end{abstract}

\section{Introduction}

Major depressive disorder (MDD) is a common mood disorder accounting for the greatest disease burden among mental disorders worldwide (Whiteford et al., 2013). Although effective treatments for MDD are available, it is estimated that about $20 \%$ of depressed patients do not recover within two years (Spijker et al., 2002). When symptoms of MDD are present for two years or longer depression is considered to be chronic (cMDD). Current treatments for cMDD include psychotherapy, antidepressants or their combination (for a review see: Spijker, van Straten, Bockting, Meeuwissen, \& van Balkom, 2013). Although psychotherapy is effective in treating cMDD, the effect sizes are rather small (Cuijpers et al., 2010) indicating that there is room for improvements. A better understanding of the mechanisms that contribute to symptom change is the key to improving current treatments (Kazdin, 2007). The overall aim of the current study was to explore the impact of two potentially important mechanisms of symptom change, maladaptive schemas and the therapeutic alliance, during psychotherapy for cMDD.

Schema therapy (ST) is a relatively new, long-term, integrative, treatment for chronic axis-I and axis-II disorders (Young, Klosko, \& Weishaar, 2003), with an established effectiveness for personality disorders (for a review see: Bamelis, Bloo, Bernstein, \& Arntz, 2012) and emerging evidence suggests that ST is also effective for cMDD (e.g. Carter et al., 2013; Malogiannis et al., 2014; Renner, Arntz, Peeters, Lobbestael, \& Huibers, 2016). We conducted a single-case series to test the effects of individual ST in 25 patients with cMDD. Relative to a no-treatment control phase, the intervention led to significant and large reductions in depressive symptom severity (Cohen's $d$ 1.22-1.30; Renner et al., 2016). While a number of studies have started to test the effects of ST for cMDD on the reduction of depressive symptoms, another relevant question is what accounts for change in

\footnotetext{
* Corresponding author. MRC Cognition and Brain Sciences Unit, 15 Chaucer Road, Cambridge, CB2 7EF, United Kingdom.

E-mail address: Fritz.Renner@mrc-cbu.cam.ac.uk (F. Renner).
} 


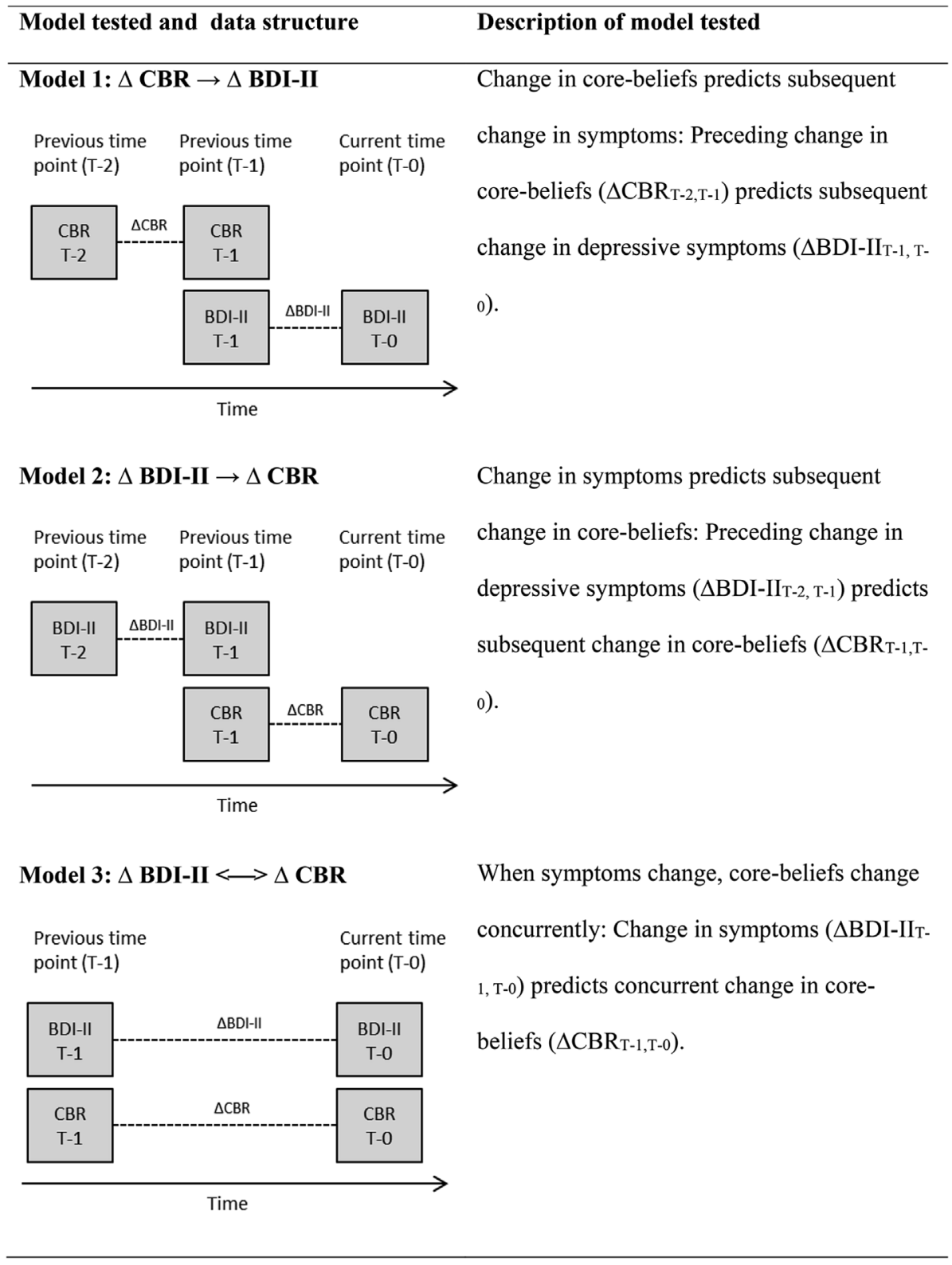

Fig. 1. Three models testing the relation between negative core-beliefs and depressive symptoms. BDI-II = Beck Depression Inventory second edition; $\mathrm{CBR}=$ Core-beliefs Ratings; $\mathrm{T}=$ Time. symptoms during treatments (i.e. what are the treatment mechanisms).

The theoretical model of ST assumes that patients with psychological problems are characterized by a distinct set of early maladaptive schemas (Young et al., 2003). These schemas determine the way in which people perceive the world, themselves and others and can have a powerful impact on sensations, emotions and behavior. The goal of ST is to decrease the impact of dysfunctional schemas and to replace them with functional schemas. Theoretically, schemas might be related to depressive symptoms in at least three different ways (Fig. 1): i) according to theory, change in schemas, drives subsequent change in symptoms during ST (Young et al., 2003), ii) contrary to theory, change in depressive symptoms drives subsequent change in schemas, iii) schemas change concurrently (i.e. at the same time) with depressive symptoms, suggesting that a third factor is driving change in both process and outcome.

Findings from previous studies that tested associations between schemas and change in symptoms during ST were mixed. Nordahl, Holthe, and Haugum (2005), for example, found that change in schemas from pre-treatment to post-treatment predicted improvements in global symptom severity in a mixed outpatient sample. In contrast,
Renner, van Goor et al. (2013) found that, in a sample of young adults with personality disorders (features) receiving a shortened group ST intervention, changes in global symptom severity accounted for changes in schemas, rather than the other way around. Importantly, these studies did not take the temporal relation between changes in schemas and symptoms into account. van Vreeswijk, Spinhoven, Eurelings-Bontekoe, and Broersen (2014) studied temporal relations between changes in schemas and changes in symptoms by assessing pretreatment to mid-treatment changes in schema severity and mid-treatment to end-treatment changes in symptoms during short term group schema cognitive behavioral group therapy. In a mixed outpatient sample they found that early changes in schemas predicted subsequent changes in symptoms as well as large concurrent associations between changes in schemas and changes in symptoms over time. While these studies provide preliminary support of temporal relations between change in schemas and change in symptoms during schema therapy, a more fine grained (session-to-session) analysis of temporal relations between schemas and symptoms during ST will further contribute to disentangling temporal relations between these variables. Thus, one aim of the current study was to explore temporal session-to-session 
associations between changes in schemas and changes in depressive symptoms during ST for cMDD.

Another potential key mechanism underlying symptom change in ST is the therapeutic alliance. The concept of the therapeutic alliance can be conceptualized as the degree to which client and therapist agree on the goals of treatment, the methods used to achieve these goals and the personal bond between client and therapist (Bordin, 1979). Research syntheses on the alliance - outcome relation have reported small to moderate correlations between the alliance and treatment outcome (e.g. Horvath, Del Re, Fluckiger, \& Symonds, 2011). Although the therapeutic alliance is usually considered a common factor in psychotherapy research, it might be an especially important contributor to outcome in ST (Spinhoven, Giesen-Bloo, van Dyck, Kooiman, \& Arntz, 2007). In ST the therapeutic alliance is used as a therapeutic technique, for example in limited reparenting in which the therapist takes the position as it were of a good parent to meet the unmet childhood needs of the client (Young et al., 2003). Similarly, imagery rescripting of traumatic experiences, a key technique in ST, likely requires a strong trust relationship between therapist and client (Hoffart, Oktedalen, Langkaas, \& Wampold, 2013). Theoretically, the therapeutic alliance might be related to change in symptoms in at least three different ways (Fig. 2): i) change in symptoms from pre-session to post-session might be predicted by the alliance rating of the session, ii) changes in symptoms prior to a session might predict subsequent alliance ratings, or iii) two repeated alliance evaluations of the same session, completed at different times, might change concurrently (i.e. at the same time) with changes in symptoms, for example because the level of depression colors the evaluation. These possible alliance outcome relations have not been addressed sufficiently in the psychotherapy outcome literature. Thus, another aim of the current study was to explore temporal associations between the alliance and changes in symptoms during ST for cMDD.

It has been argued that previous interpretations of the allianceoutcome relationship are problematic due to correlational research designs that did not disentangle the temporal relation between change in symptoms and alliance assessments (DeRubeis, Brotman, \& Gibbons, 2005). Demonstrating temporal precedence between potential mechanisms and outcomes has been described as "the Achilles heel of treatment studies" (Kazdin, 2007, p. 5). In order to demonstrate that a potential mechanism of symptom change precedes the observed effect in time it is necessary to establish a timeline (Kazdin, 2007). This requires repeated assessment of symptoms and potential mechanisms of symptom change at multiple time points during treatment. In our single case-series of ST for cMDD patients received on average 78 repeated weekly assessments during the intervention phase of the study, allowing us to map out the temporal relationships between changes in symptoms and potential mechanisms of symptom change (Renner et al., 2016). Assessments were completed weekly from home (online) and sessions were initially scheduled weekly, yet with lower frequencies later in treatment. Due to this large number of repeated assessments and the independence of assessments and sessions (assessments occurred independent of treatment sessions) we were able to establish a timeline and examine the underlying temporal relations between potential mechanisms (schemas and therapeutic alliance) and symptom change. The main outcome data reporting the treatment effects of this study are presented elsewhere (Renner et al., 2016). The current study involves an exploratory analyses of potential mechanisms of treatment effects not reported in the main outcome paper.

Repeated assessment of schemas is challenging because schemas are a highly theoretical and complex construct and usually assessed with an extensive questionnaire in ST (Young, 2006). Here we used ratings of the strength of a set of idiosyncratic core-beliefs about five domains (self, other, world, future, and interpersonal relationships) as a proxy of underlying schemas. Acknowledging that in this way we assessed only a part of what a schema can entail, we therefore refer to this variable as "core-beliefs" instead of "schema".
The overall aim of the current study was to test potential mechanisms responsible for symptom change in ST for cMDD. Specifically, we tested temporal relations between change in core-beliefs and depressive symptoms and between change in the therapeutic alliance and depressive symptoms during ST for cMDD.

\section{Method}

\subsection{Participants}

Twenty-five patients with a DSM-IV diagnosis of cMDD were included. Five patients stopped during the baseline period, before starting with the intervention. The current report is based on data from the remaining 20 patients who started with the intervention. Recruitment took place at a specialized secondary care facility in Maastricht, the Netherlands. Patients in the age range between 18 and 65 years, with a primary diagnosis of cMDD, defined as meeting the DSM-IV criteria for MDD for at least two years as assessed with the Structured Clinical Interview for DSM-IV Axis-I disorders (SCID-I; First, Spitzer, Gibbon, \& Williams, 1997) and a score of 20 or higher on the Beck Depression Inventory second edition (Beck, Steer, \& Brown, 1996) were included. Exclusion criteria were a current or past diagnosis of MDD with psychotic features; current or past bipolar disorder; current or past psychotic disorder; alcohol or drug dependence or autism spectrum disorder, as assessed with the SCID-I. Moreover, patients with a clusterA or cluster-B personality disorder as assessed with the Structured Clinical Interview for DSM-IV Axis-II Disorders (SCID-II; First, Spitzer, Gibbon, \& Williams, 1994) were excluded. Acute suicide risk was an additional exclusion criterion. Patients taking antidepressant medication were excluded, unless they were stable on medication for at least three months prior to the screening procedure. ${ }^{1}$ The study protocol was approved by the medical ethical committee of the University Hospital Maastricht and the local ethics committee of the specialized secondary mental health facility where treatment was provided. All patients enrolled in the study signed written informed consent.

\subsection{Measures}

\subsubsection{Beck Depression Inventory - second edition (BDI-II)}

Depressive symptom severity was assessed with the BDI-II (Beck et al., 1996). The BDI-II assesses depressive symptom severity along 21items with increasing severity ranging from 0 to 3 with higher scores representing more symptom severity. The Dutch version of the BDI-II that was used in this study has good psychometric properties (van der Does, 2002). The instructions of the original BDI-II were adapted in the current study, asking participants to evaluate depressive symptoms during the past week instead of the past two weeks.

\subsubsection{Session rating scale (SRS)}

The quality of the therapeutic alliance was assessed with the SRS (Duncan et al., 2003). The SRS is a brief, 4-item, instrument based on the definition of the therapeutic alliance by Bordin (1979) and measures the relational bond between client and therapist, goal agreement, and task agreement. An overall scale assesses whether the client feels that "there was something missing in the session" vs "overall the session was good for me" along a $100 \mathrm{~mm}$. Visual Analogue Scale (VAS; Duncan et al., 2003). We used the overall scale in all analyses and additional analyses for the bond, goal and task subscales are reported. Participants completed the SRS weekly and the instructions were to rate the last treatment session. Satisfactory psychometric properties have been reported for the SRS (Duncan et al., 2003).

\footnotetext{
${ }^{1}$ Medication dosage of one participant taking venlafaxine was increased from $75 \mathrm{mg}$ to $150 \mathrm{mg}$ two months prior to start of the study.
} 


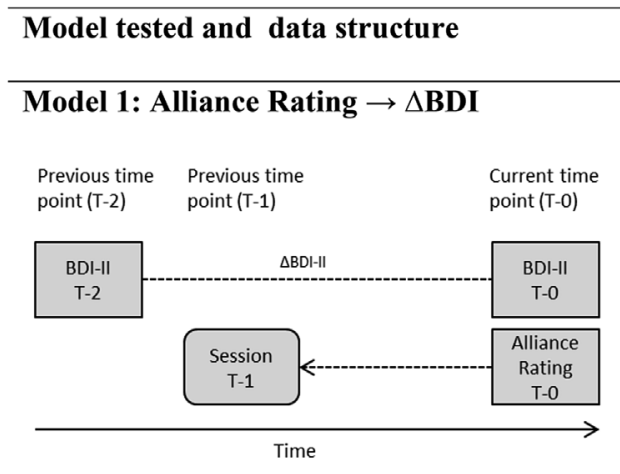

Note. The alliance rating at $\mathrm{T}-0$ reflects the

rating of the last treatment session (T-1).

\section{Model 2: $\triangle$ BDI $\rightarrow$ Alliance Rating}

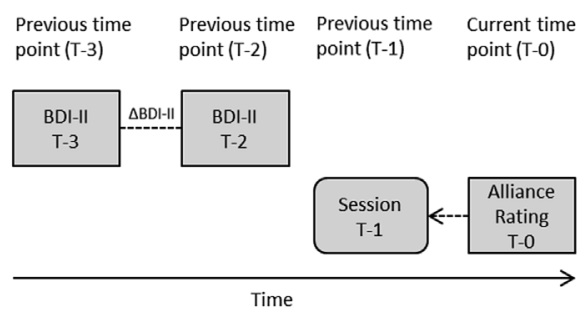

Note. The alliance rating at $\mathrm{T}-0$ reflects the

rating of the last treatment session (T-1).

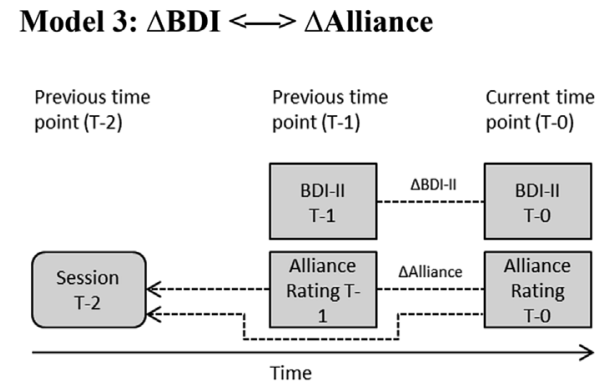

\section{Description of model tested}

\author{
Therapeutic alliance predicts symptom \\ change: Change in depressive \\ symptoms from pre-session (BDI-II T- \\ 2) to post-session (BDI-II T-0) is \\ predicted by the therapeutic alliance \\ rating (T-0) of that session (T-1).
}

Symptom change predicts therapeutic

alliance: The alliance rating (T-0) of the

last session ( $\mathrm{T}-1)$ is predicted by change

in depressive symptoms prior to the

session $(\Delta \mathrm{BDI} T-3, \mathrm{~T}-2)$.

Symptoms and alliance change ratings

change concurrently: Change in two

subsequent alliance ratings ( $\Delta$ Alliance

Rating $\mathrm{T}-1, \mathrm{~T}-0)$ of the same session ( $\mathrm{T}$ -

2 ) is concurrently related to change in
Fig. 2. Three models testing the relation between the therapeutic alliance and depressive symptoms. 
Table 1

Results of mixed regression analyses testing the relation between change in core-beliefs and change in depressive symptoms.

\begin{tabular}{|c|c|c|c|c|c|}
\hline & Beta & $S E$ & $D F$ & $t$ & $p$ \\
\hline \multicolumn{6}{|l|}{ Model 1} \\
\hline Intercept & 0.05 & 0.54 & 454.99 & 0.09 & 0.926 \\
\hline Time & -0.03 & 0.10 & 452.39 & -0.33 & 0.743 \\
\hline$\Delta \mathrm{CBR}$ & -0.09 & 0.08 & 746.10 & -1.18 & 0.238 \\
\hline Time $\mathrm{x} \Delta \mathrm{CBR}$ & 0.02 & 0.01 & 772.21 & 1.41 & 0.160 \\
\hline \multicolumn{6}{|c|}{ Model 1 after removing ns. interaction } \\
\hline Intercept & 0.09 & 0.54 & 450.92 & 0.17 & 0.862 \\
\hline Time & -0.04 & 0.10 & 448.08 & -0.51 & 0.676 \\
\hline$\Delta \mathrm{CBR}$ & 0.01 & 0.02 & 799.79 & 0.51 & 0.608 \\
\hline \multicolumn{6}{|l|}{ Model 1 final } \\
\hline Intercept & -0.13 & 0.13 & 377.74 & -1.00 & 0.318 \\
\hline$\triangle \mathrm{CBR}$ & 0.01 & 0.22 & 800.81 & 0.53 & 0.600 \\
\hline \multicolumn{6}{|l|}{ Model 2} \\
\hline Intercept & 0.14 & 0.84 & 489.93 & 0.17 & 0.867 \\
\hline Time & -0.06 & 0.16 & 486.93 & -0.36 & 0.721 \\
\hline$\Delta \mathrm{BDI}$ & -0.24 & 0.22 & 808.93 & -1.09 & 0.276 \\
\hline Time $\mathrm{x} \Delta \mathrm{BDI}$ & 0.05 & 0.04 & 808.99 & 1.32 & 0.188 \\
\hline \multicolumn{6}{|c|}{ Model 2 after removing ns. interaction } \\
\hline Intercept & 0.26 & 0.84 & 486.99 & 0.31 & 0.759 \\
\hline Time & -0.08 & 0.16 & 484.10 & -0.50 & 0.621 \\
\hline$\Delta$ BDI-II & 0.04 & 0.06 & 804.71 & 0.71 & 0.481 \\
\hline \multicolumn{6}{|l|}{ Model 2 final } \\
\hline Intercept & -0.15 & 0.19 & 417.49 & -0.75 & 0.451 \\
\hline$\Delta \mathrm{BDI}-\mathrm{II}$ & 0.04 & 0.06 & 805.64 & 0.70 & 0.485 \\
\hline \multicolumn{6}{|l|}{ Model 3} \\
\hline Intercept & 0.43 & 0.76 & 535.54 & 0.57 & 0.572 \\
\hline Time & -0.09 & 0.14 & 533.31 & -0.62 & 0.535 \\
\hline$\Delta \mathrm{BDI}$ & 0.63 & 0.21 & 871.10 & 3.01 & 0.003 \\
\hline Time $\mathrm{x} \Delta \mathrm{BDI}$ & 0.01 & 0.04 & 874.05 & 0.15 & 0.877 \\
\hline \multicolumn{6}{|c|}{ Model 3 after removing ns. interaction } \\
\hline Intercept & 0.44 & 0.75 & 537.28 & 0.58 & 0.561 \\
\hline Time & -0.09 & 0.14 & 534.92 & -0.64 & 0.524 \\
\hline$\Delta \mathrm{BDI}-\mathrm{II}$ & 0.66 & 0.05 & 872.48 & 13.23 & $<0.001$ \\
\hline \multicolumn{6}{|l|}{ Model 3 final } \\
\hline Intercept & -0.03 & 0.17 & 468.04 & -0.17 & 0.863 \\
\hline$\Delta \mathrm{BDI}-\mathrm{II}$ & 0.66 & 0.05 & 873.65 & 13.23 & $<0.001$ \\
\hline
\end{tabular}

Note. All time variables are log transformed.

consisted of up to 65 individual sessions ST lasting 50 min each. In this phase, underlying schemas, emotional experiences and dysfunctional behaviors were targeted by the use of cognitive and experiential techniques, the therapeutic alliance (limited reparenting), and behavioral techniques (Young et al., 2003). Sessions were scheduled weekly initially and with lower frequency later in treatment. A more detailed description of the treatment manual of ST for cMDD that was followed in the current study is provided elsewhere (Renner, Arntz, Leeuw, \& Huibers, 2013). All analyses reported here are based on the intervention phase.

\section{Analytical approach}

Due to the design of the study, different sequences of assessment session combinations emerged between, as well as within, participants. In most instances weekly repeated assessments of depressive symptoms, core-beliefs, and the alliance of the previous session were separated by a treatment session. Thus, in these instances the participant completed an assessment some time before and some time after a therapy session. However, in other instances, for example when sessions were not scheduled weekly, a treatment session was followed by a number of weekly assessments, resulting in repeated assessments of the therapeutic alliance of the same therapy session. Thus, in these instances the participant had a therapy session and completed at least two assessments on different days following the session. Given this data structure, we were able to test the three models of how change in corebeliefs could be related to change in depressive symptoms (illustrated and described in Fig. 1) and the three models of how change in depressive symptoms could be related to the therapeutic alliance (illustrated and described in Fig. 2).

To establish a timeline, we first computed the exact day of each session for each participant starting with day $=0$ for the first session in the intervention phase and the exact day of each assessment moment for each individual participant. For the assessment moments, the date on which a participant actually completed the assessment was used rather than the date on which the assessment was sent to the participant. When the assessment completion and the treatment session fell on the same date the exact time of the session and the exact time of the assessment were compared to determine whether the alliance rating referred to the same day session or to the previous session.

Next, each of the models described in Figs. 1 and 2 was computed per participant (details presented in Supplementary materials). To derive an aggregated coefficient of the strength of the (temporal) relations between study variables a multi-level analysis was conducted (MLA). The participant was entered as subject variable, and an index variable, starting at 0 at the first assessment for each individual and then incrementing by 1 for each subsequent assessment, was entered as repeated variable. For each model an autoregressive (AR1) covariance structure was specified. The fixed part of each model included a main effect for the predictor variable, a main effect of time as well as time $\times$ predictor interactions. Additional fixed effects for time and time $\times$ predictor interactions were specified since the strength of the core-beliefs - BDI-II relationship and the strength of the alliance - BDIII relationship might change during treatment. The optimal representation of time, represented by the session number or by the day of assessment, was derived by comparing the model fit for linear and logarithmic representations of time. Backward deletion of non-significant predictors was used, starting with the interaction, to come to a final model. The dependent variable and fixed effects were specified per model depending on the specific model that was tested (see Figs. 1 and 2). For more details on model specification see supplementary materials.

\section{Results}

\subsection{Relation between change in core-beliefs and change in depressive symptoms}

Results of the mixed regression analyses testing the relation between change in core-beliefs and change in depressive symptoms are summarized in Table 1.

4.1.1. Core-belief model 1 - change in core-beliefs predicts subsequent change in symptoms

The time $\times \Delta$ CBR interaction was not significant $(B=0.02, t$ $(722.21)=1.41, p=0.160)$ and therefore removed from the model. In the final model, the main effect of $\Delta \mathrm{CBR}$ was not significant, $\mathrm{B}=0.01, t$ $(800.81)=0.53, p=0.600$.

4.1.2. Core-belief model 2 - change in symptoms predicts subsequent change in core-beliefs

The time $\times \Delta$ BDI-II interaction was not-significant $(\mathrm{B}=0.05, t$ $(808.99)=1.32, p=0.188)$, and therefore removed from the model. In the final model, the main effect of $\triangle B D I-I I$ was not significant, $\mathrm{B}=0.04, t(805.64)=0.70, p=0.485$, showing that improvements in depressive symptoms did not predict subsequent improvements in corebeliefs.

4.1.3. Core-belief model 3 - core-beliefs and depressive symptoms change concurrently

The time $\times \Delta$ BDI-II interaction was not-significant $(\mathrm{B}=0.01, t$ $(874.05)=0.15, p=0.877)$, and therefore removed from the model. In the final model, the main effect of change in BDI-II was significant, 
Table 2

Results of mixed regression analyses testing the relation between the therapeutic alliance and changes in depressive symptoms.

\begin{tabular}{|c|c|c|c|c|c|}
\hline & Beta & $S E$ & $D F$ & $t$ & $p$ \\
\hline \multicolumn{6}{|l|}{ Model 1} \\
\hline Intercept & 1.81 & 3.02 & 285.06 & 0.60 & 0.548 \\
\hline Time & -0.02 & 0.03 & 283.74 & -0.66 & 0.512 \\
\hline Overall alliance & -1.36 & 1.16 & 305.11 & -1.17 & 0.243 \\
\hline Time x Overall alliance & 0.01 & 0.01 & 303.70 & 1.04 & 0.301 \\
\hline \multicolumn{6}{|c|}{ Model 1 after removing ns. interaction } \\
\hline Intercept & -1.05 & 1.21 & 258.34 & -0.87 & 0.385 \\
\hline Time & 0.01 & 0.01 & 262.29 & 0.78 & 0.436 \\
\hline Overall alliance & -0.17 & 0.19 & 260.30 & -0.91 & 0.362 \\
\hline \multicolumn{6}{|l|}{ Model 1 final } \\
\hline Intercept & -1.35 & 1.16 & 261.33 & -1.16 & 0.246 \\
\hline Overall alliance & 0.01 & 0.01 & 261.59 & 0.64 & 0.524 \\
\hline \multicolumn{6}{|l|}{ Model 2} \\
\hline Intercept & 80.32 & 4.57 & 107.74 & 17.56 & $<0.001$ \\
\hline Time & 2.19 & 1.45 & 108.65 & 1.51 & 0.134 \\
\hline$\Delta \mathrm{BDI}-\mathrm{II}$ & -0.43 & 0.55 & 188.90 & -0.79 & 0.430 \\
\hline Time $\mathrm{x} \Delta \mathrm{BDI}-\mathrm{II}$ & 0.15 & 0.17 & 185.32 & 0.91 & 0.364 \\
\hline \multicolumn{6}{|c|}{ Model 2 after removing ns. interaction } \\
\hline Intercept & 79.91 & 4.55 & 106.08 & 17.55 & $<0.001$ \\
\hline Time & 2.31 & 1.44 & 107.23 & 1.60 & 0.113 \\
\hline$\Delta \mathrm{BDI}-\mathrm{II}$ & 0.05 & 0.13 & 161.61 & 0.40 & 0.687 \\
\hline \multicolumn{6}{|l|}{ Model 2 final } \\
\hline Intercept & 86.60 & 1.83 & 33.50 & 47.25 & $<0.001$ \\
\hline$\Delta \mathrm{BDI}-\mathrm{II}$ & 0.05 & 0.13 & 162.55 & 0.41 & 0.684 \\
\hline \multicolumn{6}{|l|}{ Model 3} \\
\hline Intercept & -5.51 & 1.80 & 265.90 & -3.06 & 0.002 \\
\hline Time & 0.68 & 0.33 & 260.54 & 2.07 & 0.039 \\
\hline$\Delta \mathrm{BDI}-\mathrm{II}$ & 0.48 & 0.48 & 425.07 & 0.99 & 0.322 \\
\hline Time $\mathrm{x} \Delta \mathrm{BDI}$-II & -0.08 & 0.09 & 424.78 & -0.95 & 0.343 \\
\hline \multicolumn{6}{|c|}{ Model 3 after removing ns. interaction } \\
\hline Intercept & -5.48 & 1.81 & 267.97 & -3.03 & 0.003 \\
\hline Time & 0.67 & 0.33 & 262.95 & 2.05 & 0.041 \\
\hline$\Delta \mathrm{BDI}-\mathrm{II}$ & 0.03 & 0.10 & 418.85 & 0.25 & 0.799 \\
\hline \multicolumn{6}{|l|}{ Model 3 final } \\
\hline Intercept & -1.89 & 0.46 & 162.82 & -4.09 & $<0.001$ \\
\hline$\Delta \mathrm{BDI}-\mathrm{II}$ & 0.02 & 0.10 & 418.45 & 0.20 & 0.844 \\
\hline
\end{tabular}

Note. All time variables are log transformed.

$\mathrm{B}=0.66, t(873.65)=13.23, p<0.001$, showing that improvements in depressive symptoms were concurrently associated with improvements in core-beliefs.

\subsection{Relation between therapeutic alliance and depressive symptoms}

Model 1 and 2 were conducted with the log transformed session number as representation of time and with the log transformed day of assessment as additional sensitivity analyses. Model 3 was conducted with the log transformed day of assessment as representation of time because assessments for this model could also occur in the absence of a session. The results of the MLA of the alliance models are summarized below and in Table 2. All analyses were repeated separately for the subscales bond, goal and task (not reported in Table 2).

\subsubsection{Alliance model 1 - change in depressive symptoms is predicted by alliance}

The time $\times$ overall alliance interaction was not significant ( $\mathrm{B}=0.01, t(303.70)=1.04, p=0.30$ ) and therefore removed from the model. In the final model, overall alliance was not significant, $\mathrm{B}=0.01, t(261.59)=0.64, p=0.524$, showing that change in depressive symptoms from pre-session to post-session was not predicted by the therapeutic alliance of that session. Similarly, separate analyses with the bond, goal, and task subscales revealed non-significant effects. $^{2}$

\subsubsection{Alliance model 2 - change in depressive symptoms predict alliance ratings}

The time $\times \Delta$ BDI-II interaction was not significant $(\mathrm{B}=0.15, t$ $(185.32)=0.91, p=0.364)$ and therefore removed from the model. In the final model, $\triangle$ BDI-II was not significant, $\mathrm{B}=0.05, t$ $(162.55)=0.41, p=0.684$, showing that changes in depressive symptoms prior to a session did not affect alliance ratings of the session. Similarly, separate analyses with the bond, goal, and task subscales revealed non-significant effects as did sensitivity analyses with the logtransformed day of assessment as time variable.

4.2.3. Alliance model 3 - two subsequent alliance ratings of the same session change with changes in mood state

The time $\times \Delta$ BDI-II interaction was not significant $(\mathrm{B}=-0.08, t$ (424.78) $=-0.95, p=0.343$ ) and therefore removed from the model. After removing the ns interaction there was a significant main effect of time, $\mathrm{B}=0.67, t(262.95)=2.05, p=0.04$, showing that in situations in which the therapeutic alliance of the same session was evaluated twice, on separate days, the second evaluation was more negative and that this effect was more profound in early phases of treatment but leveled out throughout treatment. In the final model, $\Delta$ BDI-II was not significant, $\mathrm{B}=0.02, t(418.45)=0.20, p=0.844$, showing that changes in the overall alliance rating of the same session did not vary with concurrent changes in depressive symptoms.

In the model including the bond subscale change score as dependent variable, the time $\times \Delta$ BDI-II interaction was not significant, $\mathrm{B}=-0.11, t(425.82)=-1.27, p=0.21$, and therefore removed from the model. After removing the ns interaction there was a significant main effect of time $\mathrm{B}=0.75, t(268.31)=2.22, p=0.027$, showing that bond ratings increased over time. In the final model, the main effect of bond was not significant, $\mathrm{B}=-0.14, t(421.68)=-1.31$, $p=0.190$. In the model including the goal subscale change score as dependent variable, the time $\times \Delta$ BDI-II interaction was significant, $\mathrm{B}=-0.30, t(424.64)=-3.00, p=0.003$. Similarity, in the model including the task subscale change score as dependent variable, the time $\times \Delta$ BDI-II interaction was significant, $B=-024, t$ $(427.60)=-2.73, p=0.007$. To interpret the meaning of these interaction terms, we plotted the predicted change in the goal and task subscales, derived from the MLA, against change in BDI-II scores with separate lines representing different phases of treatment (Fig. 3). ${ }^{3}$. In general, repeated goal and task agreement ratings of the same session became more positive in situations in which depressive symptoms decreased concurrently, whereas goal and task agreement ratings of the same therapy session became more negative in situations in which depressive symptoms increased concurrently. In the first quartile of treatment this general pattern was reversed, such that repeated goal and task agreement ratings of the same session became more negative in situations in which depressive symptoms decreased concurrently and more positive in situations in which depressive symptoms increased concurrently (Fig. 3).

\section{Discussion}

The aim of this study was to test potential mechanisms of symptom change in schema therapy (ST) for chronic major depressive disorder

\footnotetext{
${ }^{2}$ Additional sensitivity analyses included MLAs with the log-transformed day of assessment as time variable and analyses in which only pre-session assessments were considered that occurred two days or less before the session because it could be argued that it is more likely that the session causes change in symptom severity from pre-session to post-session if the session occurs relatively shortly after the initial pre-session BDI-II assessment. These sensitivity analyses resulted in comparable results.

${ }^{3}$ To test the robustness of these findings, we conducted sensitivity analyses in which only instances were included in which two assessments moments occurred after a session because these alliance ratings might be more accurate. In these sensitivity analyses weighted concurrent correlations and results of MLA were comparable to those of the initial analyses.
} 


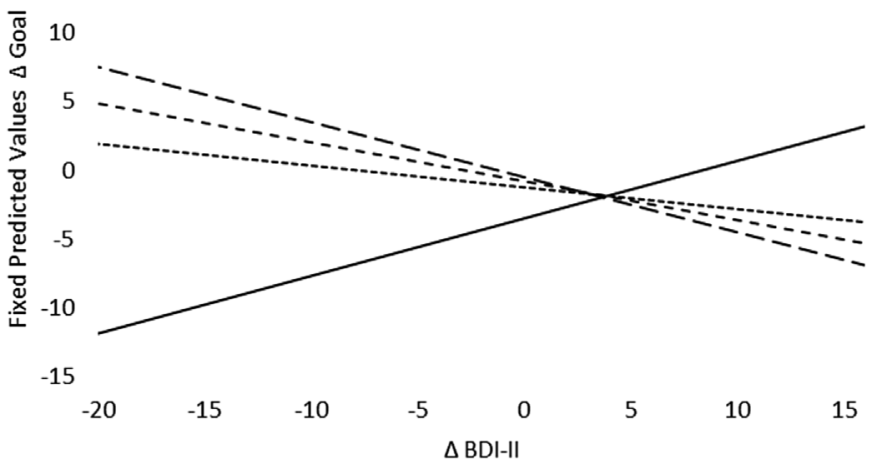

10

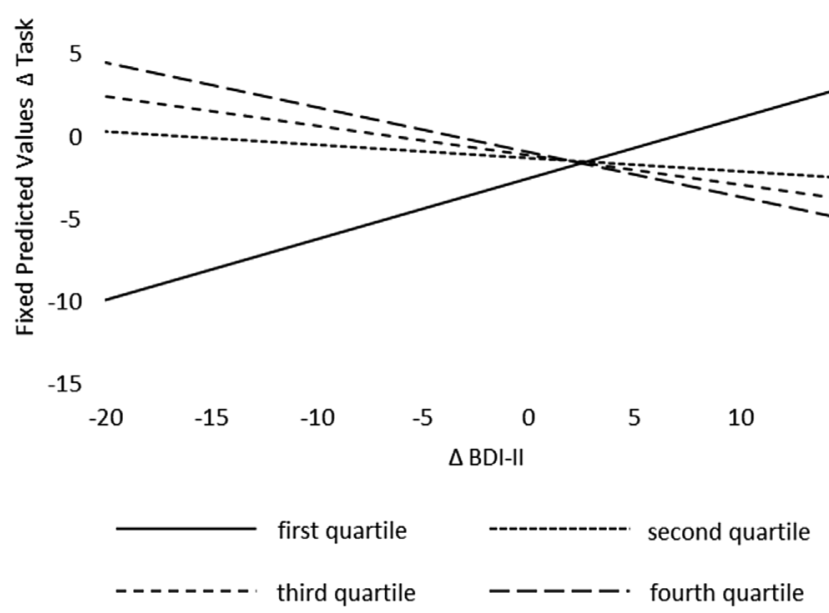

Fig. 3. Illustration of the significant time $\times \Delta$ BDI-II interactions predicting concurrent change in goal agreement (panel A) and task agreement (panel B).

(cMDD). We focused on two potential key mechanisms of symptom change in ST, schemas (as proxied by negative idiosyncratic core-beliefs) and the therapeutic alliance. An innovative approach to study the temporal relation among these variables was applied, focusing on the within-person variance, i.e. differences in changes in these variables over time within participants. We tested six models of how negative core-beliefs and the therapeutic alliance might be related to changes in depressive symptom severity during ST for cMDD (Figs. 1 and 2).

Changes in negative core-beliefs did not predict subsequent changes in symptoms (core-belief model 1), as theory would suggest (Young et al., 2003), and changes in depressive symptoms did not predict subsequent changes in negative core beliefs (core-belief model 2). Analyses of the concurrent core-belief model (core-belief model 3) suggest that changes in negative core-beliefs go together with concurrent changes in depressive symptoms. In other words, when symptoms improve core-beliefs improve concurrently.

The most robust evidence was found for a concurrent relation between changes in core-beliefs and changes in depressive symptoms. One explanation for this finding could be that both measures might partly assess the same overall symptomatic distress factor. Another possibility is that improvement in both variables is driven by another, unknown process. Yet another explanation could be that the timing of assessments did not capture the timing in which changes in these variables took place and that an even more fine grained temporal analyses of processes is necessary to disentangle the temporal relations between these variables. For example, it is possible that change in negative-core beliefs drives subsequent change in symptoms on the following day. With the current frequency of weekly assessments this would be erroneously reflected in a concurrent relation rather than a temporal relation between these variables. More fine grained analyses of temporality with repeated assessments every day (e.g. experience sampling) might shed more light on these process outcome relations, however practically it might be difficult to use such methodology over a very long treatment duration such as in ST for cMDD.

The question of when changes in negative schemas occur and how this can be assessed is also relevant in the context of the broader question of what accounts for change in negative schemas. Based on theory it would be expected that the specific techniques used in ST would account for change in schemas during treatment. However, there is also evidence that Early Maladaptive Schemas, as assessed with the Young Schema Questionnaire, improve following psychological treatment for depression that does not specifically target negative schemas (Wegener, Alfter, Geiser, Liedtke, \& Conrad, 2013) and following outpatient treatment with psychotherapy and/or antidepressants (Renner, Lobbestael, Peeters, Arntz, \& Huibers, 2012). It should be noted that in these studies improvements in schemas was relatively small compared to improvements in depressive symptoms (Renner et al., 2012). What accounts for change in schemas during treatment is an issue for future research using appropriate assessment frequencies and control groups.

Another potential mechanism that might explain symptom change in ST for cMDD that was tested in the current study is the therapeutic alliance. In general, we found no evidence that the therapeutic alliance of a session was related to change in depressive symptoms from presession to post-session (alliance model 1). Thus our findings suggest that the alliance does not predict symptom change, when the temporal relation between alliance ratings and assessments of depressive symptoms is taken into account. Research synthesis on the alliance - outcome relation have reported small to moderate positive associations between alliance ratings and treatment outcome (Horvath et al., 2011). However, these previous studies primarily relied on cross-sectional research designs, focusing on differences in alliance ratings between subjects when predicting treatment outcome rather than changes in alliance ratings within-subjects over time. Typically, in these studies between subject differences in alliance ratings assessed at the beginning of treatment are related to between subject differences in treatment outcomes. In the current analyses, repeated alliance ratings within-individuals were related to session-to-session changes. If the alliance would be related to better outcomes than this should be reflected in positive associations between session-to-session changes and alliance ratings of the session (alliance model 1) but this was not supported in the current study. Moreover, we found no evidence for the second alliance model, stating that changes in depressive symptoms prior to a session would predict the subsequent alliance rating of the session.

The most robust evidence in the current study was found for the model predicting a concurrent association of changes in alliance ratings of the same therapy sessions and concurrent changes in depressive symptoms (alliance model 3). Findings of the current study suggest that changes in depressive symptoms are concurrently related to changes in the goal and task subscales of the alliance and that the strength of this association varies over the course of treatment. In particular, we found that repeated goal and task agreement assessments of the same session became more negative in situations in which depressive symptoms increased concurrently, indicating that alliance assessments are partly colored by the current level of depressive symptoms. Moreover, in an early treatment phase, this pattern was reversed showing that improvements in depressive symptoms were associated with more negative ratings of the goal and task agreement. One explanation for this finding might be that early on in treatment patients do not attribute improvements in symptoms to the specific techniques used in treatment whereas later on in treatment improved symptoms might be more readily attributed to the specific techniques (task agreement) used in treatment, resulting in the positive associations found in this study. Change in ratings on the bond subscale of the alliance did not relate to concurrent changes in depressive symptoms. This is consistent with previous findings showing that the alliance-outcome correlation is 
primarily driven by task and goal agreements rather than the bond of the therapeutic relationship (Webb et al., 2011).

Results of previous studies testing temporal alliance - symptom change associations over treatment were mixed with some studies showing that improvements in the alliance predict subsequent symptom improvements (e.g. Falkenstrom, Ekeblad, \& Holmqvist, 2016; ZilchaMano, Dinger, McCarthy, \& Barber, 2014) whereas other studies did not find consistent support for this association once other factors are controlled for (e.g. Strunk, Cooper, Ryan, DeRubeis, \& Hollon, 2012; Webb, Beard, Auerbach, Menninger, \& Bjorgvinsson, 2014). Comparisons of findings among studies testing alliance - outcome relations is complicated by differences in methodology and treatments under study. Few studies tested temporal alliance - outcome relations in comparative treatment trials for depression. Lemmens et al. (2017) explored temporal relations between potential mechanisms (including the therapeutic alliance) and change in depressive symptoms based on data from a recent RCT comparing Cognitive Therapy and Interpersonal Therapy for depression (Lemmens et al., 2015). They found no evidence for temporal relations between change in the therapeutic alliance and change in depressive symptoms, suggesting that improvements in alliance do not predict subsequent improvements in depressive symptoms in the treatments under study. As the authors note, one potential explanation for the lack of temporal relations between potential mechanisms and outcome might be that the timing of assessments is often too spaced (Lemmens et al., 2017). The current study adds to previous studies exploring temporal alliance - outcome associations by showing that repeated session-to-session alliance assessments of the same session vary with session-to-session changes in symptom levels. Future studies investigating temporal alliance - outcome associations should further seek to determine the optimal assessment frequency of mechanisms and outcomes.

In the context of ST the therapeutic alliance might be considered as an especially important potential contributor to outcome (Spinhoven et al., 2007). Although we did not find evidence for temporal relations between improvements in alliance ratings and improvements in symptoms, this finding is not inconsistent with the idea that the alliance might be especially important in ST. In the current study, alliance ratings were high and remained high throughout treatment. It is possible that a certain minimum-quality of the alliance is necessary for ST techniques to be effective. However, given that a lot of effort is invested in building a strong alliance in ST this minimum requirement might be met in most cases and temporal alliance outcome relations might only be detected where there is more variation in ratings of the quality of the alliance.

The findings of the current study should be interpreted in the light of several limitations. First, by design the sample size was relatively small. It should be noted, however, that due to the frequent repeated assessments and the long duration of treatment a relatively large amount of data was available to test the proposed models. Second, we tested relatively straightforward models of how core-beliefs and the therapeutic alliance could be related to change in depressive symptoms. However, it is possible that the interrelationships between these variables are more complex but due to the relatively small sample size we were not able to test more complex multivariate models. Third, by design the current study did not include a control group and we were therefore not able to conduct formal mediation analyses. Fourth, we did not conduct objective ratings of therapist competence and adherence to the treatment protocol. Finally, we used an idiosyncratic measure to assess change in schemas over time rather than standardized measures of schemas such as the Young Schema Questionnaire. Although the therapists followed a detailed protocol to identify idiosyncratic schemas, we did not validate our idiosyncratic assessment of schemas with standardized measures of early maladaptive schemas and it therefore remains unclear if our schema measure indeed measured negative schemas.

In conclusion, the current study advances previous process outcome studies by introducing an innovative approach to study process - outcome relations. Focusing on temporal relations between changes in negative core-beliefs and changes in depressive symptoms, we conclude that changes in negative core-beliefs improve when depressive symptoms improve. Regarding the temporal precedence between the therapeutic alliance and symptom improvements, we found no evidence that change in symptoms was related to alliance ratings. Clinically, these findings suggest that it is not necessary to frequently evaluate session alliance in order to produce improvement in symptoms from pre-session to post-session. However, changes in alliance ratings correlated concurrently with changes in mood ratings suggesting that alliance ratings seem to be at least in part colored by changes in current mood state, however the directionality of this concurrent correlation remains unclear. Disentangling the temporal relations between change in symptom levels and potential common factors of change (e.g. therapeutic alliance) and treatment specific factors of symptom change (e.g. schemas) remains an important challenge for future research that is far from resolved.

\section{Conflict of interest}

None of the authors has any actual or potential conflict of interest relating to this work.

\section{Acknowledgements}

The authors would like to thank the participating patients, therapists, research coordinators and research assistants. Maastricht University and the academic community mental health center (RIAGG) Maastricht provided the financial support for this study.

\section{Appendix A. Supplementary data}

Supplementary data related to this article can be found at http://dx. doi.org/10.1016/j.jbtep.2017.10.002.

\section{References}

Bamelis, L. L. M., Bloo, J., Bernstein, D., \& Arntz, A. (2012). Effectiveness studies. In M. F. Van Vreeswijk, J. Broersen, \& M. Nadort (Eds.). The Wiley-Blackwell handbook of schema therapy: Theory, research and practice (pp. 495-510). Chichester: WileyBlackwell.

Beck, A. T., Steer, R. A., \& Brown, G. K. (1996). Manual for the Beck depression inventory - II. San Antonio, TX.

Bordin, E. (1979). The generalizability of the psychoanalytic concept of the working alliance. Psychotherapy, (16), 252-260.

Carter, J. D., McIntosh, V. V., Jordan, J., Porter, R. J., Frampton, C. M., \& Joyce, P. R. (2013). Psychotherapy for depression: A randomized clinical trial comparing schema therapy and cognitive behavior therapy. Journal of Affective Disorders, 151(2), 500-505. http://dx.doi.org/10.1016/j.jad.2013.06.034.

Cuijpers, P., van Straten, A., Schuurmans, J., van Oppen, P., Hollon, S. D., \& Andersson, G. (2010). Psychotherapy for chronic major depression and dysthymia: A meta-analysis. Clinical Psychology Review, 30(1), 51-62. http://dx.doi.org/10.1016/j.cpr.2009.09. 003.

DeRubeis, R. J., Brotman, M. A., \& Gibbons, C. J. (2005). A conceptual and methodological analysis of the nonspecifics argument. Clinical Psychology: Science and Practice, 12(2), 174-183. http://dx.doi.org/10.1093/clipsy/bpi022.

van der Does, A. J. W. (2002). Handleiding: De Nederlandse versie van de Beck Depression Inventory, 2de Editie [The Dutch version of the Beck Depression Inventory, 2nd ed]. Lisse: Swets and Zeitlinger b.v.

Duncan, B. L., Miller, S. D., Sparks, J. A., Reynolds, L. R., Brown, J., \& Johnson, L. D. (2003). The session rating Scale: Preliminary psychometric properties of a "working" alliance measure. Journal of Brief Therapy, 3(1), 3-12.

Falkenstrom, F., Ekeblad, A., \& Holmqvist, R. (2016). Improvement of the working alliance in one treatment session predicts improvement of depressive symptoms by the next session. Journal of Consulting and Clinical Psychology. http://dx.doi.org/10.1037/ сср0000119.

First, M. B., Spitzer, R. L., Gibbon, M., \& Williams, J. B. W. (1994). Structured clinical interview for DSM-IV Axis II personality disorders (SCID-II). New York: New York State Psychiatric Institute, Biometrics Research Department.

First, M. B., Spitzer, R. L., Gibbon, M., \& Williams, J. B. (1997). Structured clinical interview for DSM-IV Axis I disorders (SCID-I). New York: Biometrics Research Department.

Hoffart, A., Oktedalen, T., Langkaas, T. F., \& Wampold, B. E. (2013). Alliance and outcome in varying imagery procedures for PTSD: A study of within-person processes. 
Journal of Counseling Psychology, 60(4), 471-482. http://dx.doi.org/10.1037/ a0033604.

Horvath, A. O., Del Re, A. C., Fluckiger, C., \& Symonds, D. (2011). Alliance in individual psychotherapy. Psychotherapy (Chic), 48(1), 9-16. http://dx.doi.org/10.1037/ a0022186.

Kazdin, A. E. (2007). Mediators and mechanisms of change in psychotherapy research. Annual Review of Clinical Psychology, 3, 1-27.

Lemmens, L. H. J. M., Arntz, A., Peeters, F., Hollon, S. D., Roefs, A., \& Huibers, M. J. H. (2015). Clinical effectiveness of cognitive therapy v. interpersonal psychotherapy for depression: Results of a randomized controlled trial. Psychological Medicine, (Ci), 1-16. http://dx.doi.org/10.1017/S0033291715000033.

Lemmens, L. H. J. M., Galindo-Garre, F., Arntz, A., Peeters, F., Hollon, S. D., DeRubeis, R. J., et al. (2017). Exploring mechanisms of change in cognitive therapy and interpersonal psychotherapy for adult depression. Behaviour Research and Therapy, 94, 81-92. http://dx.doi.org/10.1016/j.brat.2017.05.005.

Malogiannis, I. A., Arntz, A., Spiropoulou, A., Tsartsara, E., Aggeli, A., Karveli, S., ... Zervas, I. (2014). Schema therapy for patients with chronic depression: A single case series study. Journal of Behavior Therapy and Experimental Psychiatry, 45(3), 319-329. http://dx.doi.org/10.1016/j.jbtep.2014.02.003.

McBride, C., Farvolden, P., \& Swallow, S. R. (2007). Major depressive disorder and cognitive schemas. In L. P. Riso, P. L. Du Toit, D. J. Stein, \& J. E. Young (Eds.). Cognitive schemas and core beliefs in psychological problems. A scientist-practitioner guide. Washington: American Psychological Association.

Nordahl, H. M., Holthe, H., \& Haugum, J. A. (2005). Early maladaptive schemas in patients with or without personality Disorders: Does schema modification predict symptomatic relief? Clinical Psychology \& Psychotherapy, 12(2), 142-149. http://dx. doi.org/10.1002/cpp.430.

Renner, F., Arntz, A., Leeuw, I., \& Huibers, M. (2013a). Treatment for chronic depression using schema therapy. Clinical Psychology Science and Practice, 20, 166-180. http:// dx.doi.org/10.1111/cpsp.12032.

Renner, F., Arntz, A., Peeters, F. P., Lobbestael, J., \& Huibers, M. J. (2016). Schema therapy for chronic depression: Results of a multiple single case series. Journal of Behavior Therapy and Experimental Psychiatry, 51, 66-73. http://dx.doi.org/10.1016/ j.jbtep.2015.12.001.

Renner, F., Lobbestael, J., Peeters, F., Arntz, A., \& Huibers, M. (2012). Early maladaptive schemas in depressed patients: Stability and relation with depressive symptoms over the course of treatment. Journal of Affective Disorders, 136(3), 581-590. http://dx.doi. org/10.1016/j.jad.2011.10.027.

Renner, F., van Goor, M., Huibers, M., Arntz, A., Butz, B., \& Bernstein, D. (2013b). Shortterm group schema cognitive-behavioral therapy for young adults with personality disorders and personality disorder features: Associations with changes in symptomatic distress, schemas, schema modes and coping styles. Behaviour Research and Therapy, 51(8), 487-492. http://dx.doi.org/10.1016/j.brat.2013.05.011.

Spijker, J., de Graaf, R., Bijl, R. V., Beekman, A. T., Ormel, J., \& Nolen, W. A. (2002).
Duration of major depressive episodes in the general population: Results from The Netherlands mental health survey and incidence study (NEMESIS). British Journal of Psychiatry, 181, 208-213. Retrieved from http://bjp.rcpsych.org/content/181/3/ 208.full.pdf.

Spijker, J., van Straten, A., Bockting, C. L. H., Meeuwissen, J. A. C., \& van Balkom, A. J. L. M. (2013). Psychotherapy, antidepressants, and their combination for chronic major depressive disorder: A systematic review. The Canadian Journal of Psychiatry/La Revue canadienne de psychiatrie, 58(7), 386-392.

Spinhoven, P., Giesen-Bloo, J., van Dyck, R., Kooiman, K., \& Arntz, A. (2007). The therapeutic alliance in schema-focused therapy and transference-focused psychotherapy for borderline personality disorder. Journal of Consulting and Clinical Psychology, 75(1), 104-115. http://dx.doi.org/10.1037/0022-006x.75.1.104.

Strunk, D. R., Cooper, A. A., Ryan, E. T., DeRubeis, R. J., \& Hollon, S. D. (2012). The process of change in cognitive therapy for depression when combined with antidepressant medication: Predictors of early intersession symptom gains. Journal of Consulting and Clinical Psychology, 80(5), 730-738. http://dx.doi.org/10.1037/ a0029281.

van Vreeswijk, M., Spinhoven, P., Eurelings-Bontekoe, E. H. M., \& Broersen, J. (2014). Changes in symptom severity, schemas and modes in heterogeneous psychiatric patient groups following short-term schema cognitive-behavioural group therapy: A naturalistic pre-treatment and post-treatment design in an outpatient clinic. Clinical Psychology \& Psychotherapy, 21, 29-38.

Webb, C. A., Beard, C., Auerbach, R. P., Menninger, E., \& Bjorgvinsson, T. (2014). The therapeutic alliance in a naturalistic psychiatric setting: Temporal relations with depressive symptom change. Behaviour Research and Therapy, 61, 70-77. http://dx. doi.org/10.1016/j.brat.2014.07.015.

Webb, C. A., DeRubeis, R. J., Amsterdam, J. D., Shelton, R. C., Hollon, S. D., \& Dimidjian, S. (2011). Two aspects of the therapeutic alliance: Differential relations with depressive symptom change. Journal of Consulting and Clinical Psychology, 79(3), 279-283. http://dx.doi.org/10.1037/a0023252.

Wegener, I., Alfter, S., Geiser, F., Liedtke, R., \& Conrad, R. (2013). Schema change without schema therapy: The role of early maladaptive schemata for a successful treatment of major depression. Psychiatry, 76(1), 1-17. http://dx.doi.org/10.1521/ psyc.2013.76.1.1.

Whiteford, H. A., Degenhardt, L., Rehm, J., Baxter, A. J., Ferrari, A. J., Erskine, H. E., .. Vos, T. (2013). Global burden of disease attributable to mental and substance use disorders: Findings from the global burden of disease study 2010. The Lancet, 382(9904), 1575-1586.

Young, J. E. (2006). Young schema Questionnaire-3. New York: Cognitive Therapy Center. Young, J. E., Klosko, J., \& Weishaar, M. E. (2003). Schema therapy: A practitioner's guide. New York: Guilford Press.

Zilcha-Mano, S., Dinger, U., McCarthy, K. S., \& Barber, J. P. (2014). Does alliance predict symptoms throughout treatment, or is it the other way around? Journal of Consulting and Clinical Psychology, 82(6), 931-935. http://dx.doi.org/10.1037/a0035141. 